\title{
Voltando ao começo: desvelando os bastidores políticos da Lei Paulo Delgado
}

\author{
Going back to the beginning: unveiling the political background of the \\ Paulo Delgado Law
}

Paulo Gabriel Godinho Delgado*1

DOI: 10.1590/0103-11042020E303

No início era o deputado dos loucos, depois meus adversários me chamavam de o deputado louco... Tem até Caps com meu nome em cidades do Brasil... Hoje sou profissional liberal; e quando vocês ainda me procuram, sinto algo como se a vida passasse aos trancos e barrancos, mas sempre volta ao comecco, sem se deter.

*Sociólogo. Professor aposentado da Universidade Federal de Juiz de Fora (UFJF). Deputado da constituinte de 1988, exerceu mandatos de deputado federal até 2011.

1 Pesquisador autônomo Minas Gerais, Brasil. pauloggdelgado@gmail.com

\section{Origens: a defesa do paciente psiquiátrico}

No início, quando imaginamos a reintegração do paciente psiquiátrico à vida, nós pensamos que poderíamos fazer isso do ponto de vista exclusivamente legal, de que era possível, mudando a lei, mudar o costume.

A história da lei tem a força das ondas: é meio uma onda que vai e vem, constrói e desconstrói. Quando se tem que criar instituições e equipamentos novos, também temos que estar preparados para criar uma nova institucionalização.

A sociedade estava em ebulição com o movimento da reforma sanitária que criou o Sistema Único de Saúde (SUS), a partir da oitava Conferência de Saúde, e os movimentos sociais emergentes que exigiram a constituinte. E foi neste ambiente que fui procurado em Juiz de Fora, como deputado constituinte eleito por Minas, pelo Movimento Nacional da Luta Antimanicomial. No Hotel Joalpa, em 1978, seus líderes me apresentaram a proposta de ser um deputado dedicado a defender o paciente psiquiátrico. Defender o doente mental brasileiro da estigmatização, do processo de isolamento, do tratamento indevido, da sedação excessiva e de tudo que compunha o universo da interdição compulsória, da tutela, da curatela, o universo predominante na psiquiatria brasileira. Assim foi feito e debatido o projeto. Um projeto de formulação simples do ponto de vista legal e que consistia em deter a expansão de leitos e redirecionar os recursos para o tratamento aberto. Era a primeira fase da ação legal, cuja ordem era parar de construir e abrir novos leitos em hospital fechado. Qualquer coisa que significasse voltar a ter leito como centro da atenção seria uma regressão.

A segunda direção significou livrar o doente mental do estigma da periculosidade e da incapacidade civil permanente. Essa era a fase mais complexa, cultural, que esbarrava no preconceito disseminado e na desinformação. Daí a ideia de fazermos logo a Lei das Cooperativas Sociais e, dentro da ideia do Programa do Benefício da Prestação Continuada, previsto na Lei 
Orgânica da Assistência Social (Loas) (uma lei mais da assistência social para descapacitados), ir criando as condições para outras leis correlatas, como o Programa de Volta para Casa (esta lei dentro da concepção do direito para injustiçados). Tudo era parte de um mesmo modelo de desmanicomialização da vida social.

A ideia central era a de que se retiro o paciente do hospital, fecho o hospital 'especializado', tenho que abrir outros serviços alternativos ou substitutivos. Assim nasceram os Centros de Atenção Psicossocial (Caps), pioneiros da nova mentalidade que contém a perspectiva de reinserção social de um novo cidadão. Modelo que já existia na história da saúde pública no Brasil e tem na doutora Nise da Silveira, no Rio de Janeiro, na Casa das Palmeiras, um grande exemplo. Esse modelo trabalhava com a arte como estímulo à liberdade e ao resgate da humanidade esquecida de esquizofrênicos. A ideia da Cooperativa Social tem esse objetivo inicial de oferecer alternativas de trabalho produtivo segundo as condições do paciente, atraindo o interesse da sociedade para outro sentido de produtividade do trabalho.

O terceiro passo, que era um dos mais importantes, depois de ter a construção, pensar na reinserção, era definir o orçamento. $\mathrm{Na}$ verdade, esse continua sendo o primeiro, a condição do passo seguinte, integral, que é definir para onde vão os recursos da saúde. Nesse aspecto, teve papel importante a continuidade da visão antimanicomial que prevaleceu nas diversas gestões da Coordenação de Saúde Mental do Ministério da Saúde dos anos 1990 até a gestão Tykanori em 2015.

Foram essas várias coordenações do período da reforma psiquiátrica como nós entendemos, impulsionadas pelo Projeto de Lei de 1989, e depois pela Lei $\mathrm{n}^{\circ} 10.216 / 2001$, que iniciaram e conduziram, de maneira ativa, a prática do modelo novo, como o fez pioneiramente Domingos Sávio com as portarias que tornaram o Caps uma realidade. Ao diversificar os métodos e técnicas terapêuticas para compatibilizar e classificar a remuneração do atendimento com a prática antimanicomial que o ministério visava, Domingos deu um tiro mortal no dinheiro do hospício e se fez o pai do Caps. Naquela época, a Lei no 3.657/1989 já estava aprovada na Câmara e era debatida no Senado.

\section{Hospício: hospitalidade e prisão}

É bom sempre lembrar que hospício, etimologicamente, vem de hospitalidade, hotel, quarto de hóspede, aquele lugar da casa onde você recebe seus amigos. Quando o conceito se degradou e se tornou sinônimo de impiedade e prisão, nasceu junto o conceito negativo na cabeça dura da medicina psiquiátrica tradicional, que insiste em associar doença mental com internação e isolamento. Coisa absolutamente sem sentido, porque a doença mental, não sendo contagiosa, não precisa de isolamento. Em caso de surto, você precisa proteger o paciente no surto, e não agravar sua crise com a desumanização da atenção. Ou seja, os alicerces da Reforma, sua base, são os princípios do SUS.

A ideia de evitar a desterritorialização, acolher o paciente perto do lugar onde ele vivia é fundamental. Dessa ideia, surgiu o Programa de Volta para Casa, no qual muitos se reinseriram, voltaram à convivência. Tivemos casos de casamentos de pacientes que ficaram vinte, trinta anos internados, saíram e se casaram. Outro princípio é o da Integralidade, quer dizer, ter todos os recursos da medicina à disposição das pessoas, sem distinção nenhuma, como está no art. $5^{\circ}$ da Constituição brasileira.

\section{Apoios políticos e cautela}

Tivemos grandes relatores de plenário, como o governador de São Paulo, Geraldo Alckmin, um médico que muito ajudou. Mas, até Darcy Ribeiro foi pressionado no Senado pela Associação Mundial de Psiquiatria, presidida por um influente psiquiatra do Rio de Janeiro com quem conversei no Jockey Club 
pedindo sua compreensão. Costa Silva era claro ao propor que se salvasse o Hospital Psiquiátrico da degola. Tinha background junto aos Senadores. Era um ex-Diretor da Divisão de Saúde Mental da Organização Mundial da Saúde (OMS). Quando Lúcio Alcântara, senador, ex-governador e médico, aceitou relatar sem medo, temi por ele, não pela lei. Nós nunca o homenageamos como ele merece.

Muitos setores do movimento me criticavam porque achavam que eu era mineiro demais. Tinha momento que, para salvar a lei, era preciso aceitar emendas, tirar de pauta, engolir relatores. O parlamento não é monarquia. Havia essas ondas conservadoras que estão voltando. Sempre havia essas ondas. Fomos cautelosos. Não mexemos, por exemplo, na legislação sobre o louco infrator. As medidas de segurança. $\mathrm{O}$ movimento da luta antimanicomial decidiu separar isso, faziam várias reuniões se tomavam as decisões tecnicamente, politicamente e ponderavam comigo. Achavam, com razão, que não era possível entrar ao mesmo tempo com a nova lei sobre a custódia. Era melhor separar os dois públicos, vamos dizer assim, o mundo do louco normal e o do infrator. Porque, na verdade, o louco infrator é outra lei. É uma lei penal, envolve a justiça criminal e a psiquiatria forense.

\section{Descentralizar para existir: as experiências locais}

Quando eu digo que nós aproveitamos muito a estrutura federal do Brasil, e demos uma dimensão federal, é que quando começou essa dúzia de anos de espera, de luta, quando começou a ter muita dificuldade à lei nacional, nós começamos a descentralizar a luta da lei. E fomos organizadamente para os estados. E veio o Ceará, o Espírito Santo e o Rio Grande do Sul. E isso foi uma surpresa para o sistema nacional psiquiátrico.

A Associação Brasileira de Psiquiatria, que nos apoiava em um determinado período, começou a se assustar porque a lei federal não saía, mas começaram a sair leis estaduais, regionais. Aí veio também Pernambuco, Minas
Gerais e Brasília. Ou seja, as leis foram pipocando. Com isso, nós fomos criando um ambiente nacional favorável à reforma. Começaram a surgir também secretários de saúde bem progressistas, Caps maravilhosos, que enfrentavam esse problema da desinstitucionalização que a Fernanda Nicácio estudou muito bem, publicando um livro muito oportuno'.

As visitas do Franco Rotelli ao Brasil ajudaram muito; teoricamente, quando havia uma grande dúvida, havia sempre uma consulta internacional. Outros italianos e os espanhóis também vinham muito aqui, todo o lugar que tinha um movimento mais ou menos organizado. Lembro que, na Argentina, a província de Rio Negro tinha um movimento muito forte. Estive lá a debater sobre a desmanicomialización que se fazia na Argentina. $\mathrm{Na}$ época, no parlamento latino-americano, eu era o presidente do grupo brasileiro e tentei introduzir a lei nos parlamentos da América Latina. Conversei com vários colegas, deputados latino-americanos. Contudo, a cultura é muito diferente, os países são quase todos fechados, todos manicomiais, foi incrível.

\section{As primeiras leis estaduais e seus autores}

Os autores das oito leis estaduais iniciais são fundamentais, pois deram dimensão federalista aos princípios da reforma. A maioria em governos progressistas, claramente de esquerda. Quase que virou uma lei vermelha. Começou pelo Ceará, no governo do Ciro Gomes; no Espírito Santo, com o Victor Buaiz; e no Rio Grande do Sul, com o governo do Alceu Collares. Os autores foram Mário Mamede no Ceará, Lelo Coimbra no Espírito Santo, e, no Rio Grande do Sul, Marcos Rollim, de quem me lembro bem pela sofisticação da sua defesa, e que virou meu colega na Câmara em seguida.

Depois a lei seguiu em Brasília, com Cristovam Buarque, e em Pernambuco, com Miguel Arraes; e Humberto Costa, que criou 
o Programa de Volta para Casa como ministro da Saúde, foi o autor da iniciativa do executivo. Chegou então a Minas, Rio Grande do Norte e Paraná, nos governos do Eduardo Azeredo, Garibaldi Alves e Jaime Lerner; com autoria do Carlão (Antônio Carlos Pereira), do Raimundo Bezerra e do Dr. Rosinha, que se tornou deputado federal comigo.

\section{Lei e serviço: o Caps não pode desaparecer}

Depois da lei, voltar a explorar o doente mental beira ao obsceno.

Essa Comissão Intergestores Tripartite (CIT) ${ }^{2}$ de 2017 é a cara de gestor insensível, não é o rosto da vida de quem sabe que o doente mental não é um pacote de sintoma controlado por gananciosos que lucram com o sofrimento dos outros.

A 10.216 é uma das poucas leis brasileiras que criou um serviço. É raro isso. Eu vejo colegas que fizeram boas leis, mas não criaram serviço algum. Ela criou um procedimento interdisciplinar e participativo. Então o Caps é uma conquista brasileira, um nome brasileiro para a medicina moderna. Não podemos deixar o Caps desaparecer. Nós não podemos desistir, temos que lutar, arrumar aliados no Congresso Nacional, no Ministério Público, no poder judiciário e nas famílias, para que o equipamento novo predomine sobre o velho. Isso que vai fazer o velho se tornar desnecessário e desaparecer.

\section{Memória a preservar: somos todos candidatos a pacientes}

Continuo otimista, solidário e seguirei lutando para criar a universidade antimanicomial, multidisciplinar, algo que possa ser médica, terapêutica, cultural, produtiva, reunir toda a produção editorial do movimento da luta antimanicomial, publicar, fazer os anais da luta antimanicomial, que é isso que vocês estão fazendo. A Fundação
Oswaldo Cruz (Fiocruz) e vocês têm um papel importantíssimo na memória da luta antimanicomial brasileira. Fico muito feliz de poder ser um dos porta-vozes desse movimento. E de todas as minhas conferências, inclusive nos debates, sempre que eu sou convidado, e se posso ir, eu vou a todos os lugares que me chamam. E sempre brinco, quando eu falo:

eu não sou médico, não sou psiquiatra, não sou terapeuta, não sou assistente social, não sou psicólogo, não sou enfermeiro, não sou auxiliar de enfermagem, sou candidato a paciente. E se eu pirar, quero ser tratado em um Caps.

É o que todos deviam pensar, porque as pessoas que não apoiam a reforma psiquiátrica é porque ou não conhecem seus princípios, ou acham que não vão pirar.

\section{Origens do SUS e a 'descoberta' da lei}

Quando me levaram a ideia da lei, lá em Juiz de Fora, estava acabando a constituinte, e lá estavam os princípios do SUS na nova Constituição brasileira. O movimento sanitário inscreveu o SUS na Constituição. Aqueles princípios do SUS eram o esboço, o rascunho de onde partiria para cumprir meu papel de fazer a lei, traduzir em termos técnicos os passos da lei.

Quando tomei conhecimento do universo da loucura que a lei enfrentaria e o bem que faria, se não falei, deveria ter falado para aqueles ativistas da reforma psiquiátrica que foram conversar comigo: "essa não é uma lei inventada, vocês a descobriram, essa lei está sendo descoberta”. 'Descoberta' porque a cada princípio que colocavam para mim, eu percebia a relação com outras experiências que já existiam. É como mostrar a você uma joia e você descobrir que é ouro, prata, ou seja, o material já existe na realidade, já havia gente fazendo aquilo, pensando daquele modo, já existiam famílias insatisfeitas com o modelo da internação via clausura. Os pacientes, nem se fala! 
Jorravam exemplos do que já existia: a Casa das Palmeiras; o Núcleo de Atenção Psicossocial (Naps) da Itapeva, criado pelo Jairo Goldberg, batizado de Luiz Cerqueira, outro pioneiro, em uma mansão perto da avenida Paulista; a Rádio Tam-Tam; o sequestro da Tutu Quadros, minha colega constituinte, internada à força por questões familiares; a luta da Juliano Moreira contra o ministro que mandou tanque de guerra para acabar com uma greve dentro do hospício que se agitava. A partir daí, fui ficando mais informado, e quando enfrentava todos aqueles que me criticaram, mentindo às vezes, ao dizer que não levava em conta o sofrimento das famílias, em embates com alguns familiares, eu dizia: "essa lei não éfeita para os pais, é feita para os filhos", ou falava com o filho: "a lei não foi feita para você, foi feita para o seu pai”. Essa lei foi feita para quem precisar dela!

Na verdade, ela foi descoberta por isso, porque todos sabem que por mais profissional, mais sério e competente que seja um médico, se ele está diante de um familiar, de uma pessoa que ama, tem um afeto mais profundo, respeita essa pessoa, o paciente faz dele a segunda pessoa naquele tratamento.

\section{Redimensionando o lugar social do doente psiquiátrico}

Essa desmaterialização da vida produzida pela arrecadação fria de impostos sem destinação social, ou destinação para políticas públicas erradas, isso também é um fator de desequilíbrio do processo de reforma psiquiátrica no Brasil. No balanço geral, ele começa a ser considerado secundário como se fosse pequeno o número de brasileiros que precisam da atenção básica, preventiva no SUS e nos serviços criados pela reforma psiquiátrica. Esses serviços são os que podem também sustentar a reforma e enfrentar algumas questões negativas que aponto, as que me parecem mais relevantes: o silêncio da universidade, o problema do crack e a questão da psiquiatrização de todos os problemas; porque onde estão os serviços bons que criamos, não tem crítica à lei. É boa a lei, e muito simples. E o SUS do Brasil é único, é o mais universal serviço de saúde pública do mundo. É o único lugar em que o familiar, o usuário e o profissional participam. O único lugar do mundo que está na agenda pública do dia a dia. Isso não tem aqui na América Latina, em lugar nenhum. $\mathrm{Na}$ Europa, o Estado de Bem-Estar Social parece mais sólido, mas, nosso SUS, é mais integrador, descentralizado, integral e com controle social.

Quem o sabota é a indústria de medicamentos que manda no Ministério da Saúde, a medicina comercial que atravessa com desrespeito qualquer valor humano nessa área $\mathrm{e}$ a justiça que inventou o caminho do privilégio para alguns furarem fila ou terem acesso a medicamentos não aprovados pela saúde pública. É claro que, em nosso meio, continuam a haver as internações de veludo, o império da banalidade hospitalar que nos sufoca em todos os campos da medicina, internações que não são compatíveis com a natureza da doença mental, porque a doença mental não é contagiosa, ela não requer internação nem do rico, nem do pobre. A doença mental precisa de escuta. É claro, no surto, você não vai internar a pessoa, vai acolhê-la, cuidar dela um pouco mais de tempo no sistema de observação. É uma maior intensidade do tratamento. Mas, não significa reclusão, interdição, tutela. Que é uma característica da medicina brasileira.

A medicina brasileira é carceral, ela adora internar, adora leito. Leito hospitalar, AIH (Autorização de Internação Hospitalar), não combina com psiquiatria. Tudo que um paciente precisa é de ar, andar, falar, se movimentar, precisa se deslocar. Preso ao leito, ele terá outra doença. Nós já evoluímos com a presença da lei, porque lá nos anos 1980 havia UTIs de doente mental, como se o fígado e o coração de um doente mental fossem diferentes. Isso felizmente terminou, como a lobotomia terminou. Mas ainda existem essas inconsistências, incoerências e barbaridades na observação da doença mental. 


\section{A lei e os direitos humanos: a cidadania do louco}

Uma lei que incorporou o louco brasileiro no estatuto universal dos direitos humanos das Nações Unidas, é essa sua maior marca. Ou seja, nasceu o louco cidadão e cresceu o debate sobre as razões da tutela e o interesse pelas conexões entre cidadania, justiça e a psiquiatria como bem sintetizava, desde o título, o livro do Pedro Gabriel, meu irmão e principal idealizador do meu papel como deputado antimanicomial ${ }^{3}$. Se você me perguntar, no fundo, no fundo, 'Paulo, o que ficou desse ambiente, de toda essa luta parlamentar?', ficou o louco cidadão, eu te direi. Uma insolência em um país como o Brasil tão indiferente à verdadeira significância das pessoas.

O louco sendo o cidadão que não era. O louco que era marginalizado, insignificante para a vida social. A Cooperativa Social, então, nos deu fôlego para avançar, deu certo aqui, deu ali, quando muitos Caps começaram a trabalhar com seu princípio integrador. Aprovada a lei, tivemos que enfrentar a questão da alta assistida e, daí, em mais um descortino da equipe da gestão do Pedro Gabriel na Coordenação de Saúde Mental, nasceu o Projeto de Lei ${ }^{\circ}$ $1.152 / 2003$, do ministro Humberto Costa. Esse projeto virou a Lei Ordinária $n^{\circ} 10.708 / 2003$, em que foi proposto o Programa de Volta para Casa, como determina a Lei ${ }^{0} 10.2016$, para pacientes longamente internados e de grave dependência institucional. Foi uma das coisas mais bonitas do pós-lei. Pedi urgência, articulamos todas as relatorias de Comissão em plenário e aprovamos logo. Com a redução de leitos, a expansão dos Caps e de outros Serviços Residenciais Terapêuticos, a reforma ficou de pé, ou melhor, de tripé. O reencontro com familiares depois de longos anos, a alegria que foi a devolução da liberdade a milhares de pessoas, o casamento entre pacientes. É como se tivéssemos descoberto um planeta novo. O humanismo articulado com o domínio técnico da questão se sobrepondo à cegueira dos insensíveis. Devo isso a vocês, e basta isso para justificar toda a minha vida parlamentar.

Mas, tudo começou mesmo para valer muito antes, como já disse, quando o Domingos Sávio, que era o coordenador de saúde mental do Ministério da Saúde na época, se antecipou à lei e editou as portarias que permitiram criar o Caps e que depois a lei consolidou. Por isso vejo que temos que ter muito cuidado na luta pela institucionalização-desinstitucionalização. Lutar contra más portarias, apoiar boas portarias, nós sempre podemos revogar o ruim e exaltar, melhorar o novo.

Tenho esperança, não acho que é o fim do mundo se nos mantivermos unidos em torno do objetivo maior que é a questão humanitária que sempre ameaça nossa sociedade pela via da política. Evidentemente que há um sinal do fim do mundo, mas ainda não é o fim do mundo. Existem Caps com serviço comunitário e produtivo de cooperativa no ritmo e compreensão dos pacientes, e é muito bom, interativo, com música, artesanato, alimentos. Há pintores, artistas, visão e perspectiva profissionalizante. Nós podemos avançar para uma cota de paciente psiquiátrico em todos os setores onde for possível se a indiferença social com os doentes mentais persistir.

\section{Do local para o mundo: 'Não devemos fazer nada em estado de desespero'}

Assim, voltando à história da discussão nos anos 1990, uma terceira estratégia na aprovação da lei, com o Caps e as Cooperativas Sociais, foi lutar pela aprovação das leis estaduais. Como não conseguíamos aprovar a lei nacional, mas eu também não a deixava morrer, era, assim, uma coisa, não passa a favor, mas também não enterra. Aí começamos com as leis estaduais, como já vimos. Começou lá no Ceará, que apresentou na assembleia em 1992. As leis foram aparecendo, até que a lei nacional foi aprovada naquele abril de 2001. Em 2002, ela foi sancionada. É uma lei que nasceu no governo 
do Fernando Henrique, tramitou no governo do Sarney, do Color, do Itamar, nos dois Fernando Henrique e foi sancionada no primeiro Lula.

É uma lei que tem a cara do Brasil, eu acho, por isso ela está aí até hoje. Esse ato agora, do Ministério da Saúde (CIT) é um ato historicamente equivocado de um governo isolado. Primeiro porque não pega, não se implanta. Não se consegue nessa área uma contracorrente muito forte. Porque, se aumentam os recursos para internação e volta o hospital psiquiátrico especializado, você reinaugura o manicômio. Isso, na verdade, entra em confronto com a política nacional de direitos humanos. O passo seguinte é ter que revogar também os princípios dos direitos humanos, e isso não vai conseguir se encaixar no SUS, no princípio do controle social do SUS. Como o SUS prevê a descentralização, só por isso a portaria é inconstitucional. Pode-se entrar com uma Adin, Ação Direta de Inconstitucionalidade, e o Supremo, certamente, vai julgar procedente. O princípio da integralidade também, de que todos têm direito a um tratamento completo, inclui o Caps. Aí já é uma segunda inconstitucionalidade e inconsistência, uma portaria não pode ser maior que uma lei. $E$ confronta $o$ SUS, o SUS é uma lei constitucional. O terceiro princípio que é o princípio do controle social, esse então é mortal para essa portaria, porque o controle social permite que um gestor local não aplique a portaria, mesmo que ela tenha vindo de uma instância tripartite. A autoridade gestora tem autonomia. Como prefeito, como secretário de saúde do município, é possível dizer que essa lei aqui não se aplica.

É evidente que é preciso sustentação social e jurídica para isso, e tal sustentação vem dos princípios do SUS e da política nacional de direitos humanos. Nós somos signatários da Declaração Universal dos Direitos humanos e dos seus desdobramentos que vieram com a Conferência de Viena, onde estive como chefe da delegação brasileira em 1993. Lá está escrito que o doente mental é cidadão. Portaria inócua não passa, ela não se afirma.
É um ato de arbítrio, ou de desinformação, ou pior, pressão comercial da indústria de medicamentos. Porque é mais fácil dar remédio em hospital do que tratar em casa. Porque remédio e hospital são uma rotina, como se fossem a mesma coisa.

Acho que o movimento deve ter tranquilidade, os profissionais, os técnicos, todas as pessoas das áreas, os usuários, os familiares, todos que se preocupam devem ter tranquilidade que isso não vai passar, isso não sobrevive. Não devemos fazer nada em estado de desespero.

\section{Nota de produção}

Este artigo de opinião foi consolidado a partir do extrato de uma entrevista em profundidade concedida ao Núcleo de Saúde Mental, Álcool e outras Drogas, da Fiocruz Brasília, no escopo das pesquisas 'Memórias da Saúde Mental: Cultura, Comunicação e Direitos Humanos' e 'Avaliação do Programa de Volta para Casa', entre julho de 2017 e dezembro de 2018. A primeira entrevista com Paulo Delgado foi realizada em 15 de dezembro de 2017, no aeroporto de São Paulo, em uma 'janela de tempo' entre voos de Delgado; e a segunda, em 25 de janeiro de 2018. Desde então, trabalhamos na degravação do texto e ajustes de fidedignidade com o próprio autor. O documento na íntegra possui 60 páginas e versão em áudio e vídeo, que permanecem inéditos. Cabe destacar que esse testemunho reflexivo é parte de um conjunto documental composto por mais 24 entrevistados de relevo no cenário da Reforma Psiquiátrica Brasileira e será disponibilizado na íntegra nos canais de Ciência Aberta da Fiocruz em 2020/2.

\section{Colaborador}

Delgado Paulo (0000-0003-0251-9976)* é responsável pela elaboração do manuscrito.
${ }^{*}$ Orcid (Open Researcher and Contributor ID). 


\section{Referências}

1. Nicácio F, organizadora. Desinstitucionalização. São Paulo: Hucitec; 1990.

2. Brasil. Ministério da Saúde. Comissão Intergestores Tripartite: Resolução ${ }^{\circ}$ 32, de 14 de dezembro de 2017. Diário Oficial da União. 22 Dez 2017 [acesso em 2020 set 9]. Disponível em: http://www.lex.com. br/legis_27593248_RESOLUCAO_N_32_DE_14_DE DEZEMBRO_DE_2017.aspx.
3. Delgado Pedro. As Razões da Tutela, Psiquiatria, Justiça e a Cidadania do louco no Brasil, Rio de Janeiro: Te Corá; 1992.

Recebido em 01/03/2020

Aprovado em 19/08/2020

Conflito de interesses: inexistente

Suporte financeiro: não houve 